\section{No health without mental health}

\section{Cristina Vladu, Andrei Novac, Adrian Preda, Robert G. Bota \\ University of California, Irvine, CA, USA}

Two hundred years ago, the term psychiatry was introduced (psyche-soul and iatros-physician) to designate a medical specialty that would attend to those with mental illness. ${ }^{1}$ At that time psychiatric conditions were recognized as being at the border of medicine, philosophy and theology. We are now ushering in an era in which psychiatry and primary care are creating a new alliance. We live in a world of postmodern psychiatry in which numerous previous structures and roles are being challenged. Postmodernism and neo-pragmatism have brought us deconstruction. ${ }^{2}$ It applies to many a change that modern research and new demands of society have exerted on contemporary psychiatry. Public opinion about mental illness has changed. New patient populations have emerged. The emphasis on multidisciplinary approaches has often lagged behind. Today the complexity of psychiatry among all other medical specialties is rarely recognized. A rather reductionistic over-identification with neuroscience has often been professed and a simplistic acceptance that a part is in fact the whole has been too often purported. Yet unquestionable remains the fact that psychiatric morbidity and disability outweigh the burden of other medical conditions and that our patients are the same people seen in primary care settings for most medical conditions.

As a consequence, a heavy burden is paid by the world community. It is then on this note that the World Psychiatric Association Congress in Bucharest, Romania, June 24-27, entitled: Primary Care Mental Health: Innovation and Transdisciplinarity, stands out among most other international conferences of the past year.

Recognizing the urgency to addressissues of health policy globally, the 2015 World Psychiatric Association International Congress presented the following resolutions, which were approved by the participants and will be forwarded to the United Nations: ${ }^{3}$

«WHEREAS, cardiovascular and mental disorders lead in the global burden of non-communicable diseases; WHEREAS, most mental disorders are attended to in primary care; WHEREAS, mental disorders account for $30-45 \%$ of the global burden of disability; WHEREAS, 50\% of mental disorders exist by age 14, and 75\% by age 24; WHEREAS, these disorders result in billions of dollars of negative economic consequences across low-, middle-, and high-income nations; WHEREAS, significant global health systems fragmentation diminishes access to care and its effectiveness; WHEREAS, more research into the brain and into the determinants of health is needed; WHEREAS, effective treatments for mental disorders exist for most cases; and WHEREAS, the collaboration and integration of primary care, mental health, and public health is proven to enhance access, quality, and sustainability [...]

NOW BE IT RESOLVED THAT United Nations member states adopt collaborative and integrated care as a means toward achieving total health for all in the 21st Century; and be if further resolved that [...] this goal be included in the updated United Nations Sustainable Development Goals; and be it further resolved that, United Nations member states allocate the necessary human, financial, and technological resources for training, education, and implementation of this resolution [sic]».

Many topics presented at the Congress were pertinent to health policy. Therefore, our team further interviewed many presenters and inquired about the foremost urgent aspects that need to be addressed in the process of integrating mental health into primary care. The points below summarize the comments and our observations

i) Psychiatric disorders account for a significant share of the global burden of disease. Psychiatric illness are characterized by very high comorbidity with medical and other psychiatric disorders. Therefore, they constitute a major public health burden.

ii) Current health systems are unprepared to address the ever-increasing needs of patients suffering from mental illness. Financial resources allocated for mental health are far from being proportional with the burden and prevalence of the mental disorders. Striving for adequate resources is of utmost importance.

iii) The modern health care emphasis on biological formulations for urgent or acute care is poorly fitted to address the needs of most psychiatric patients, who suffer from chronic conditions with important psychosocial determinants. 4 To improve the somatic and mental health outcomes of the people suffering with mental illness the future systems of care should consider the needs of chronic care and the psychosocial context.

iv) The complexity, chronicity and comorbidity of most psychiatric conditions requires a reconceptualization of mental health and illness across the levels of individual patient care, community care, health care organizations and policies, emphasizing the bi-directional relationships between mental and somatic illness.

v) As reflected in most of the presentations
Correspondence: Robert G. Bota, UC Irvine Health Neuropsychiatric Center, 101 The City Drive South, Orange, CA 92868, USA.

Tel.: + 1.714.456.2056.

E-mail: rbota@uci.edu

Key words: psychiatry; mental health; WPA.

Contributions: the authors contributed equally.

Conflict of interest: the authors declare no potential conflict of interest.

Received for publication: 20 May 2016.

Accepted for publication: 20 May 2016.

This work is licensed under a Creative Commons Attribution-NonCommercial 4.0 International License (CC BY-NC 4.0).

(C) Copyright C. Vladu et al., 2016

Licensee PAGEPress, Italy

Mental Illness 2016; 8:6609

doi:10.4081/mi.2016.6609

of the WPA 2015 in Bucharest and given the precarious state of the health care services provided to the mentally ill worldwide, there is an urgent need to re-conceptualize and reform the health delivery systems for the mentally ill. The new approach should be guided by principles of social justice and dignity. Patients with psychiatric disorders should be given the same priority and importance as patients with all other medical conditions.

vi) The fragmentation of most current health care services decreases the quality of care for patients with mental illness. By integrating psychiatric and other medical services future care services will foster health, improve efficiency, decrease waste and improve the overall experience of patients. ${ }^{3}$

vii) A new approach to psychiatry should include the entire spectrum of services from primary prevention to treatment and rehabilitation services for the mentally ill.

viii) Sustained integration and coordination of services between family medicine, primary health care teams and the psychiatric care at the front end is needed.

ix) As it is known that stable long-term functioning teams of professionals produce better treatment outcomes, a new approach should rely on such teams, enabling the provision of continuous and tailored care to mentally ill.

x) The PHC/community care teams should have an increasingly developed role; the WHO chronic care model should be applied and tools to activate communities should be used. Screening tools should be given to cover the most prevalent psychi- 
atric disorders. A range of evidence-based cost-effective interventions should be taught and applied by these teams.

xi) A new approach to medical education should include early exposure of medical students and other trainees to behavioral sciences and to the development of interpersonal skills and team building approach to enhance the cultural competence of the health care workers.

It is our hope that the congress has created a critical mass for a new direction in the world community of psychiatry and primary care.

\section{References}

1. Marneros A. Psychiatry's 200th birthday. Br J Psychiatry 2008;193:1-3.

2. McGowan Jr. Postmodernism and its critics. Ithaca, NY: Cornell University Press; 1991.

3. World Psychiatry Association. Bucharest statement of collaborative and integrated care. 2015. Available form: http//www.wpa 2015 bucharest.org/download-files /uGZfrv3.pdf. Accessed on: July 2015.
4. World Health Organization. Innovative care for chronic conditions: building blocks for action: global report. 2002. Available from: http://www.who.int/chp/ knowledge/publications/icccglobalreport.p df. Accessed on: July 2015. 